ECOLOGICA, Vol. 28, No 103 (2021), 426-434

https://doi.org/10.18485/ecologica.2021.28.103.13

Originalni naučni rad

UDC: 629.7.014:502.131.1

\title{
Primena bespilotnih letelica u monitoringu životne sredine
}

\section{Application of unmanned aerial vehicles in environmental monitoring}

\author{
Prof. dr Vlado Radić ${ }^{1 *}$, Doc. dr Nikola Radić ${ }^{2}$ \\ 1,2Visoka škola za poslovnu ekonomiju i preduzetništvo, Mitropolita Petra 8, 11000 Beograd, Srbija / \\ Faculty of Business Economics and Entrepreneurship, Mitropolita Petra 8, 11000 Belgrade, Serbia \\ *Autor za prepisku / Corresponding author
}

Rad primljen / Received: 09.12.2020, Rad prihvaćen / Accepted: 10.08.2021.

Sažetak: U mnogim čovekovim aktivnostima postoje ograničenja i nemogućnost njihove realizacije. Ljudi su nemoćani pred mnogim ćudima prirode, nemaju odgovor na zemljotrese, poplave, erupcije vulkana, na narušavanje životne sredine. Ta ograničenja uslovila su da opasne, prljave i monotone poslove umesto čoveka obavljaju mašine. Mašine mogu da budu roboti, automatski uređaji, specifični alati, posebno projektovana sredstva koja smanjuju izloženost čoveka štetnim uticajima ili omogućavaju da se pojedine aktivnosti izvršavaju komfornije, sa manje napora i bezbednije. U takva sredstva se, svakako, ubrajaju i bespilotne letelice. Od početaka razvoja vazduhoplovstva, bespilotne letelice bile su izazov za naučnike i inženjere, kako sa civilnog tako i sa vojnog stanovišta. Danas je proliferacija bespilotnih letelica realnost za kreatore politika, regulatorna tela, start-up i konsolidovane kompanije. Broj razvijenih bespilotnih letelica u poslednjih 15 godina se višestruko povećao, a primećen je i značajan porast civilnih / komercijalnih platformi. Cilj rada je pregled mnogobrojnih aplikacija i prednosti bespilotnih letelica zasnovanih na njihovom sistemu pilotiranja (autonomnom ili daljinski upravljanom) i senzornima radi tačnog pozicioniranja i prikupljanja velikog broja podataka. Na osnovu ova dva faktora, bespilotne letelice su efikasno rešenje za opservaciju, inspekciju, merenje i monitoring teritorije, obezbeđujući bolju prostornu, radiometrijsku, spektralnu i vremensku rezoluciju od satelita ili bilo kog drugog vazduhoplova sa ljudskom posadom.

Ključne reči: bespilotne letelice, aplikacije, poljoprivreda, šumarstvo, životna sredina, monitoring.

\begin{abstract}
In many human activities, there are limitations and the impossibility of their realization. People are helpless before the many whims of nature, they have no answer to earthquakes, floods, eruptions of volcanoes, to environmental damage. These restrictions have conditioned that dangerous, dirty and monotonous jobs are performed by machines instead of humans. Machines can be robots, automatic devices, specific tools, specially designed means that reduce human exposure to harmful influences or allow certain activities to be performed more comfortably, with less effort and safer. Such means, of course, include unmanned aerial vehicles (UAV). From the beginning of aviation development, drones have been a challenge for scientists and engineers, both from a civilian and a military standpoint. Today, the proliferation of drones is a reality for policy makers, regulators, start-ups and consolidated companies. The number of developed UAV has multiplied in the last 15 years, and a significant increase in civilian / commercial platforms has been observed. The aim of this work is the survey of numerous applications and advantages of UAV based on their piloting system (autonomous or remotely controlled) and sensors for accurate positioning and collection of large amounts of data. Based on these two factors, drones are an efficient solution for observing, inspecting, measuring and monitoring territory, providing better spatial, radiometric, spectral and temporal resolution than satellites or any other manned aircraft.
\end{abstract}

Keywords: unmanned aerial vehicles, applications, agriculture, forestry, environment, monitoring

${ }^{1}$ orcid.org/0000-0001-5571-4244, e-mail: vlado.radic@vektor.net

${ }^{2}$ orcid.org/0000-0002-8862-3004, e-mail: bra.radici@hotmail.com 


\section{UVOD / INTRODUCTION}

Budući da su bespilotne letelice prisutne u sve većem broju aplikacija, kako vojnih tako i civilnih, i da se njihove karakteristike ubrzano poboljšavaju i unapređuju, potrebno je definisati pojam "bespilotna letelica". Američka savezna vazduhoplovna uprava (FAA) definiše bespilotnu letelicu kao "sredstvo koje se koristi ili je namenjeno za upotrebu u vazduhu, bez pilota" (FAA, 2016). Drugim rečima, bespilotne letelice uključuju sve kategorije aviona i helikoptera bez pilota, što znači da lete samostalno ili daljinski bez pilota koji njima upravlja. U Srbiji se u skladu sa Pravilnikom propisanim od strane Direktorata za civilno vazduhoplovstvo (DCV, 2020) koristi termin "bespilotni vazduhoplov". U poslednje vreme se u medijima i svakodnevnom govoru ustalio naziv "dron", koji ukazuje na bespilotne letelice. Uzevši u obzir naučni karakter časopisa i rada koji se odnosi na primenu bespilotnih letelica u monitoringu životne sredine, autori smatraju da naziv "dron" nije primeren naučnoj terminologiji, pa će koristiti naziv "bespilotne letelice" (skraćeno "BL").

Bespilotne letelice pojavile su se 1917. godine kada je američka vojska započela istraživanja i testirala ih tokom Prvog svetskog rata, a u borbenu upotrebu uvedene su tek nakon Vijetnamskog rata. Međutim, od tada je napredna komunikaciona tehnologija povećala propusnost vojnih komunikacionih satelita, razvoj navigacionih tehnologija i poboljšala sposobnost daljinskog upravljanja bespilotnim letelicama. Tokom poslednjih decenija, BL odigrale su ključnu ulogu i u nevojnim operacijama, poput humanitarne pomoći na Haitiju, otkrivanju ukopanih antipersonalnih mina u Evropi, Africi i Aziji ili NHB (nuklearno, hemijsko, biološko) izviđanju. Kada se 2011. godine desila katastrofa u japanskoj nuklearnoj elektrani Fukušima Daići, zbog izuzetno velikog nivoa radijacije prisustvo ljudi u takvom hazardnom okruženju bilo je nazamislivo. Stoga su korišćeni roboti i bespilotne letelice. Slična situacija je i sa nuklearnom elektrananom u Černobilju posle eksplozije 1986. godine - u oblast zabranjenu za ljude upućuju se bespilotne letelice i vrši monitoring teritorije.

Bespilotne letelice su letelice različitih oblika i veličina, kojima se može daljinski upravljati ili mogu samostalno leteti. Izrađuju se od lakih kompozitnih materijala kako bi se smanjila masa i povećala mogućnost promene položaja. Zbog upotrebe kompozitnih materijala visoke čvrstoće mogu leteti na velikim visinama. U principu, mogu biti opremljene širokim spektrom navigacionih sistema ili uređaja za snimanje (RGB i IC kamere, GPS). Pored male mase, prednosti korišćenja BL ogledaju se i u tome što se lako transportuju, mogu da snimaju slike visoke rezolucije, menjaju visinu leta u zavisnosti od potreba prikupljanja podataka, mogu da se kreću po terenima koji su zbog prirode prepreka nedostupni ljudima, drumskim vozilima ili drugim vazduhoplovima. Pored navedenog, najvažnija karakteristika je dostupnost podataka u kratkom vremenskom intervalu, najčešće u realnom vremenu (Simelli, Tsagaris, 2015).

Bespilotne letelice su izazvale neviđen uticaj na društvo i ekonomiju, a niski troškovi senzora integrisanih u platforme različitog dizajna pokrenuli su nove aplikaciju klijentima u civilnom sektoru (Chen et al., 2021). Na primer, novi razvoji u robotici, računarskoj viziji (kako računari postižu visok nivo razumevanja digitalne slike ili videa) i geološkim tehnologijama, sa istraživanjima i razvojem podržanim od industrije, tehnoloških centara i univerziteta, omogućavaju bolji prenos tehnologije i uvid u nova tržišta. Mada su civilne BL još uvek daleko od sistema koji se koriste u vojne svrhe, istraživanja i napredak u razvoju tehnologija mogu ponuditi profesionalne sisteme sa novim, poboljšanim i obećavajućim karakteristikama (Hassanalaian et al., 2017; DII, 2020). U tom smislu, očekuje se da će se glavni napredak $B L$ dogoditi u sledećim oblastima: 1) pojava novih senzora sa boljom geometrijskom i radiometrijskom rezolucijom i širim spektralnim opsegom, 2) evolucija novih platformi koje poboljšavaju robusnost i povećavaju autonomiju, 3) razvoj softvera - od navigacije i komunikacije do obrade i analize slika, 4) nove aplikacije u sektorima logistike, pomoći u katastrofama, bezbednosti i nadzoru, zdravstvu i pomorskoj nauci (Sah et al., 2020).

\section{MATERIJALI I METODE / \\ MATERIALS AND METHODS}

Motivi za pisanje ovog rada su višestruki. Sprovedeno je opsežno pretraživanje literature o civilnoj primeni BL u poslednjih deset godina. Cilj rada je da se prikažu ne samo tehničke mogućnosti, nego i ekonomski faktori koji itekako utiču na primenu BL. $\mathrm{U}$ radu su korišćene metode deskripcije, analize i sinteze, komparacije i analogije. Ako se isključi vojni karakter i primena BL u tom segmentu, primena $\mathrm{u}$ civilnom ili komercijalnom sektoru svake godine je sve veća. Monitoring poljoprivrednog zemljišta i zasađenih kultura, inspekcija cevovoda za gas i naftu, dalekovoda i prenosne mreže, snimanje iz vazduha postojećih i objekata u izgradnji, primena u uslovima požara, pomoć u traganju i spasavanju, meteorološkoj službi, praćenje i kontrola saobraćaja, monitoring nivoa vodotokova i kontrola poplava i zagađenja, zaštita ugroženih životinjskih vrsta, praćenje invazivnih biljnih vrsta, dokumentovanje ilegalne seče, upravljanje močvarama, krivolov i 
detekcija morskog otpada - samo su neka od područja u kojima je primena BL itekako opravdana.

Prema prognozama, proliferacija BL u nekim oblastima u periodu do 2025. godine povećaće se dva do tri puta u odnosu na današnju situaciju, pa je istraživanje tržišta BL i dešavanja na njemu naučno opravdano. Poseban akcenat, naravno, je na primeni BL u monitoringu životne sredine. Saznanje da BL koriste vladine i nevladine institucije i organizacije u velikom broju zemalja upućuje na potrebu analize potražnje za BL i regulatornog okvira njihove upotrebe. Nadasve, prikupljanje velikog broja podataka vezano je za napredak u sferi digitalnih tehnologija (senzori, internet stvari (IoT), veliki podaci i analitika, veštačka inteligencija, blokchain, robotika). Stoga je drugi cilj rada ukazivanje na značaj uvođenja novih tehnologija u mnogim sektorima, jer svako kašnjenje u ovom domenu rezultira nižom produktivnošću, većim troškovima i rizicima (Mentus, Jovanović, 2020; Ristić i dr., 2020).

\section{REZULTATI I DISKUSIJA / RESULTS AND DISCUSSION}

Budući da životna sredina predstavlja skup prirodnih i stvorenih vrednosti, čiji kompleksni međusobni odnosi čine okruženje, odnosno prostor i uslove za život, praćenje kvaliteta životne sredine, biodiverziteta, štetnih aktivnosti koje utiču na životnu sredinu, ugroženosti i degradacije te rizika po životnu sredinu ima veliki društveni značaj. Mere, uslovi i instrumenti za održivo upravljanje, očuvanje prirodne ravnoteže, celovitosti, raznovrsnosti i kvaliteta prirodnih vrednosti, te sprečavanje, kontrola i smanjenje svih oblika zagađenja životne sredine čine sistem zaštite životne sredine. Da bi taj sistem dobro funcionisao, moraju postojati neophodni kapaciteti, koji podrazumevaju ljude (pojedince i institucije), uređaje, instrumente, metode, finansije i regulatorni okvir. Ako su uvezani, čine dobru osnovu za očuvanje životne sredine u svakom pogledu. Kada su u pitanju uređaji, instrumenti i metode, pored uobičajenih postoje ili se razvijaju nova, kao što su bespilotne letelice.

lako se o upotrebi BL dosta raspravlja poslednjih nekoliko godina, one su u komercijalnoj upotrebi od 1980. godine. Međutim, njihova vrednost za društvo još uvek nije u potpunosti shvaćena. Bespilotne letelice odlikuju male dimenzije, prenosivost, kao i mogućnost brze i jednostavne instalacije na terenu.

\subsection{Primena bespilotnih letelica u poljoprivredi / Application of unmanned aerial vehicles in agriculture}

Bespilotne letelice se sve više usvajaju u poljoprivredi zbog velikog obima analiza koje mogu obaviti u relativno kratkom roku (Srivastava et al.,
2020; Krishna, 2017). Bespilotne letelice obezbeđuju monitoring zemljišta, procenu prinosa useva ili praćenje stoke, što znači da poljoprivrednici mogu biti efikasniji. Snimanje poljoprivrednog zemljišta iz vazduha može se vršiti pomoću satelita, aviona, balona i bespilotnih letelica (Sylvester, 2018). Takođe, BL se mogu koristiti za mapiranje proizvodnih područja (slika 1), klasifikaciju biljaka na proizvodnim površinama, praćenje pojave bolesti i štetočina, otkrivanje područja na kojima je došlo do stresa u biljkama usled prekomerne vode ili drugih faktora, otkrivanje površina gde se vrši zalivanje ili drenaža, procena biljne biomase, kao i praćenje korova prisutnih na proizvodnim površinama (Jang et al., 2020; Yu et al., 2020; Zhou et al., 2020; Petkovics et al., 2017).

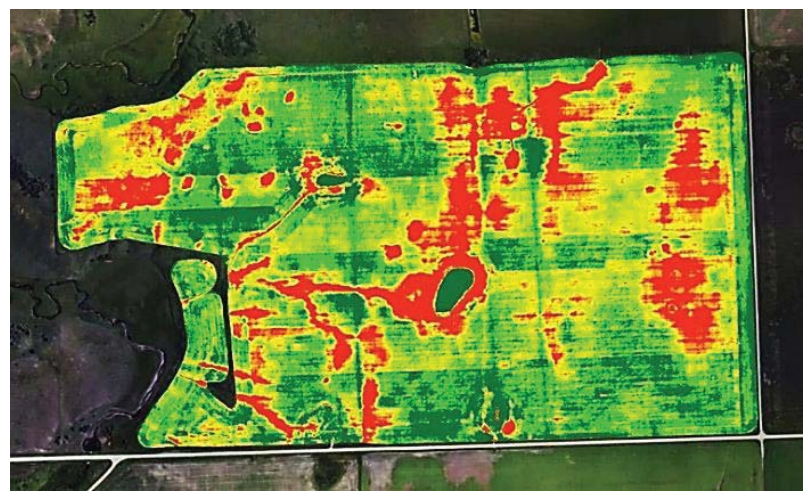

Slika 1 - Prikaz zemljišta u pregledu i mapiranju bespilotnom letelicom

Figure 1 - View of the land in the survey and mapping by unmanned aerial vehicle

$U$ poljoprivredi se $\mathrm{BL}$ koriste za obradu fotografija i dobijanje velikih količina informacija o stanju useva na zemljištu. Koriste se u hemijskoj zaštiti, setvi i zaprašivanju (Zhang, Kovacs, 2012) slika 2.

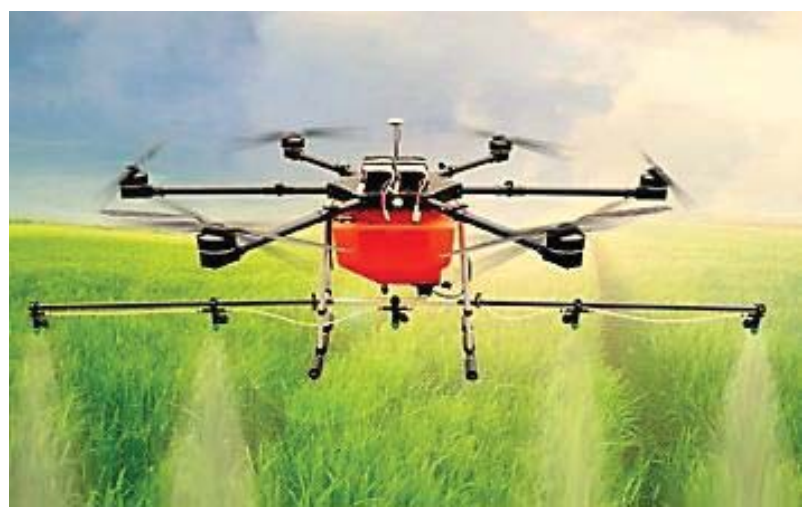

Slika 2 - Bespilotne letelice u zaprašivanju useva

Figure 2 - Unmanned aerial vehicles in crop dusting 
Prednosti korišćenja dronova u poljoprivredi su:

- omogućavaju pregled svakog dela poljoprivrednog zemljišta,

- $\quad$ spremnost, brzina pripreme i programiranje leta $\mathrm{BL}$ omogućavaju poljoprivrednicima da u kratkom vremenu pokriju velika područja,

- ne zahtevaju odlazak i smanjuju vreme provedeno na terenu zbog sagledavanja situacije,

- na osnovu prikupljenih podataka mogu se odmah donositi konkretne odluke,

- pogled iz vazduha visoke rezolucije omogućava zumiranje područja od interesa bez gubitka jasnoće (identifikacija i GPS lociranje korova, slabo nicanje useva, štete od štetočina i vremenskih nepogoda, stajaća voda),

- većina poljoprivrednika ne može "pokriti" u trenutku svoja imanja i konstatovati određene probleme (npr. pucanje cevi za navodnjavanje) koji zahtevaju hitne mere.

Najveći problemi u primeni BL u poljoprivredi vezani su vremenske prilike. U uslovima kiše ili magle, kao i jakog vetra, BL ne mogu pružiti pouzdane podatke i slike terena zahtevane rezolucije. Drugo, ne treba zanemariti ni troškove obrade podataka. Kao što je to bio slučaj sa mnogim savremenim sredstvima (računar, laptop, mobilni telefon, kamere), dostignuća u različitim naučnim oblastima izazvala su pad cena BL. Međutim, cena softvera za obradu podataka i slika još uvek je visoka, što je ograničavajući faktor u nabavci i upotrebi BL u poljoprivredi (Simelli, Tsagaris, 2015).

\subsection{Primena bespilotnih letelica u šumarstvu /} Application of unmanned aerial vehicles in forestry

Bepilotne letelice se sve češće koriste u šumarstvu, jer su pristupačnija, brža i tačnija metoda prikupljanja podataka. Bespilotne letelice mogu pratiti populaciju drveća, pejzaže i pristupiti teško dostupnim područjima. Bez upotrebe BL, ove inspekcije bile bi skupe za organizacije i institucije, a manuelno pretraživanje terena zahtevalo bi veliko vreme i veliki broj ljudi na identifkaciji problema u šumarstvu. $S$ druge strane, ljudi su ograničeni vremenom i prostorom, kao i nedostatkom pouzdanih informacija čije prikupljanje bi trajalo mnogo duže nego što traje upotrebom BL.

Prema podacima američke geofizičke unije, svake godine industrija, poljoprivreda, urbanizacija i rudarstvo unište preko 26 milijardi stabala (FAO, 2021). Rastuće krčenje šuma povezano je sa pojavom štetočina, gladi i kriza i direktno utiče na mnoge ljudske resurse. Na Pirinejskom poluostrvu, na primer, požari svake godine unište hiljade hektara šuma. Prevencija i brzi odgovor ključni su za izbegavanje situacija kao što je bila 2012.godine, kada je spaljeno područje veličine cele pokrajine Baskije. S tim ciljem na umu, Tehnički univerzitet u Madridu dizajnirao je sistem za automatsko otkrivanje šumskih požara nadzorom pomoću BL (Samaniego, 2017) - slika 3.

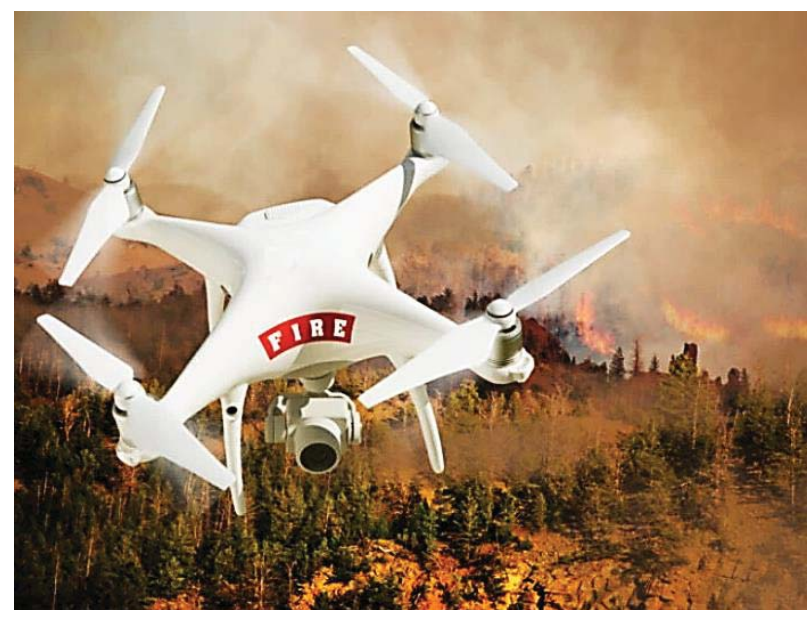

Slika 3 - Primena bespilotnih letelica u šumskim požarima

Figure 3 - Application of unmanned aerial vehicles in forest fires

Po rečima španskih istraživača, sistem je zasnovan na nizu algoritama koji omogućavaju otkrivanje plamena i dima koji nastaju u šumskim požarima, kao i zahvaćeno područje i smer vetra. Algoritmi su veoma precizni i zahtevaju male računarske kapacitete, što omogućava da se problem reši u realnom vremenu putem autonomnih sistema poput BL. Dakle, ono što postoji u stvari je kontinuirani nadzor i sistem ranog upozoravanja kako bi gašenje požara bilo efikasnije. Zanimljivo je da su se BL sa termalnim kamerama pojavile kao moćno oruđe i u drugim oblastima gašenja požara od otkrivanja nevidljivih žarišta i sprečavanja sekundarnih požara do prikupljanja podataka o požarima noću, nijedna druga tehnologija u nastajanju nije poboljšala bezbednost vatrogasaca i civila kao što su to učinile bespilotne letelice sa termovizijskim snimanjem.

Posebna problem u šumarstvu, osim ekološke štete, jeste ilegalna seča i krčenje pošumljenih terena. Do ilegalne seče i povezane trgovine dolazi kada se drvo seče, transportuje, prerađuje, kupuje ili prodaje kršeći lokalne zakone. llegalna seča postoji zbog povećane potražnje za drvetom, papirom i proizvodima od njega, uključujući ambalažu (slika $4)$. 


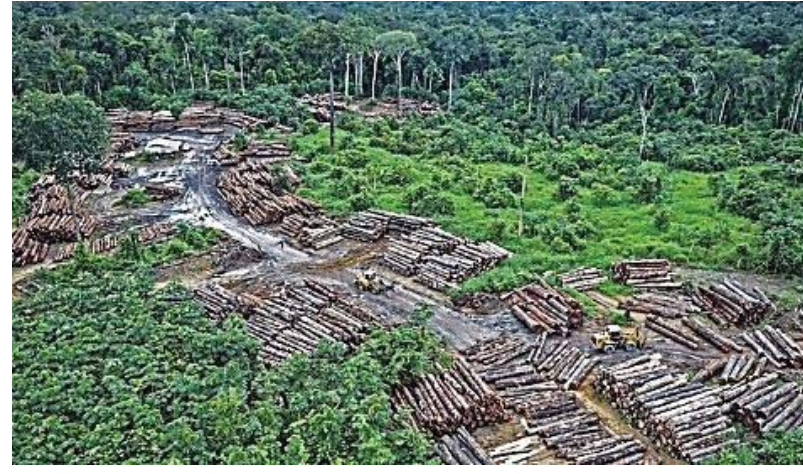

Slika 4 - Ilegalna seča šuma snimljena bespilotnim letelicama

Figure 4 - Illegal forest logging recorded by unmanned aerial vehicles

Kada se drveće seče bez odgovarajućih dozvola i krijumčari u inostranstvo, vlade gube prihode od poreza i dažbina. Studija američke asocijacije za šumu i papir procenila je da ilegalna seča smanjuje svetske cene drveta za $7 \%$ do $16 \%$, u zavisnosti od proizvoda, što uzrokuje gubitke američkih kompanija od najmanje 460 miliona dolara svake godine (CRS, 2019). Svetska banka navodi da godišnje globalno tržište gubi 10 milijardi dolara godišnje zbog ilegalne seče, a vlade gube dodatnih 5 milijardi dolara prihoda (World Bank, 2019).

Budući da je ilegalna seča prisutna na svim kontinentima, posebno u bazenu Amazona, Kongu, Kamerunu, Indoneziji, Peruu, Papua Novoj Gvineji i dr., očigledno je da se zbog izuzetno velikih prostranstava i često nedostupnih terena to može dokumentovati samo savremenim sredstvima, u koje spadaju BL. Bespilotne letelice raspolažu tehničkim uređajima respektabilnih tehničkih karakteristika i njihovom primenom eliminišu se opasnosti kojima ljudi mogu da budu izloženi tokom kontrole ili monitoringa ilegalne seče. Lokalne zajednice koriste BL na sličan način kako bi pratile zdravlje šuma. Drugi pristupi očuvanju i restauraciji zasnovani na BL su malo praktičniji. Neki zaštitari koriste $B L$ da ponovo zasade pošumljena područja, dok drugi koriste BL za otklanjanje posledica $u$ šumama, ravnicama i krčevinama, obezbeđujući put za novi rast.

\subsection{Primena bespilotnih letelica $u$ energetskom sektoru / \\ Application of unmanned aerial vehicles in the energy sector}

Solarne elektrane stvaraju čistu energiju, ne emitujući pri tome ugljen-dioksid, i na taj način ne nanose štetu životnoj sredini. Neki solarni objekti, poput onih koji se grade za napajanje data centara ili drugih velikih potrošača električne energije, mogu biti namenjeni isključivo za njihovo snabdevanje energijom. Solarne elektrane se još nazivaju i solarni parkovi, odnosno solarne farme. Instalisana snaga solarnih postrojenja na solarnim farmama može se kretati u opsegu od $10 \mathrm{MW}$ do preko 1000 MW. Prema nekim istraživanjima, potrebno je približno 25 hektara zemljišta za svakih $5 \mathrm{MW}$ snage koji mogu napajati oko 1500 kuća. Da bi se dobilo odobrenje za izgradnju solarnih elektrana potrebne su temeljne procedure planiranja. Međutim, uprkos visokim početnim troškovima izgradnje solarnih farmi, očekivani benefiti daleko premašuju inicijalni ulog. Predviđanja su da će solarna energija, u ne tako dalekoj budućnosti, zadovoljavati četvrtinu svetskih potreba za električnom energijom.

Bespilotne letelice igraju važnu ulogu u početnom planiranju lokacije, pružajući podatke o mapiranju iz vazduha. Tokom faze izgradnje, pregled napretka radova iz vazduha je takođe od velike koristi. Redovne inspekcije omogućavaju kontinuirani uvid u napredak radova i uočavanje potencijalnih problema (Lee et al., 2019). Mogućnost automatizacije putanje BL znači da se cela lokacija može detaljno pregledati i time izbeći ljudska greška u pregledu: Uostalom, pregled lokacije tolike površine iziskuje mnogo vremena i napor mnogo ljudi. Bespilotne letelice, jedna ili više u "roju" (engl. swarm), mogu izvršiti pretraživanje i pregled čitave teritorije i pružiti potrebne podatke u realnom vremenu (slika 5). $U$ fazi primopredaje, oni koji grade solarne farme mogu krajnjem korisniku dostaviti detaljan izveštaj o stanju cele lokacije koristeći snimke i podatke (informacije) prikupljene BL (Kardasz et al., 2016).

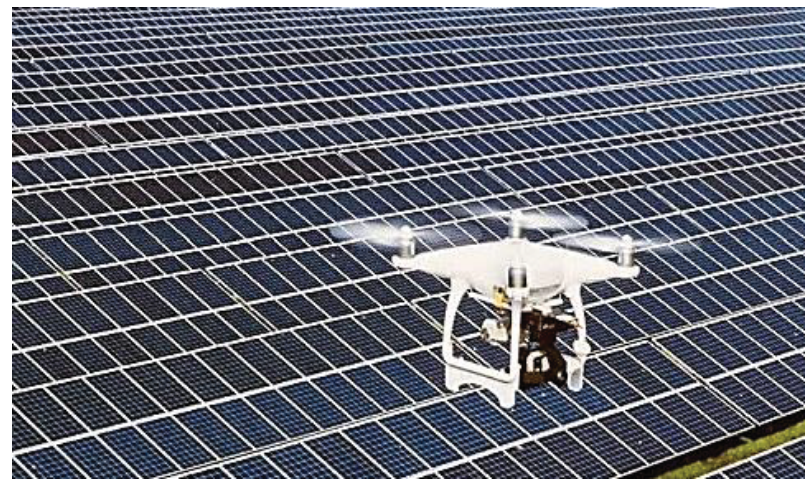

Slika 5 - Bespilotne letelice u inspekciji solarnih panela

Figure 5 - Unmanned aerial vehicles in the inspection of solar panels

Kada solarna elektrana počne sa radom, moraju se vršiti redovne inspekcije kako bi se obezbedilo da svaki panel radi efikasno. U ovim okolnostima po- 
sebno su korisne termovizijske kamere, pružajući operateru mogućnost da detektuje ploče koje uopšte ne rade ili ne rade efikasno. Takvi paneli se popravljaju ili zamenjuju drugim bez potrebe za stalnim slanjem i praćenjem njihovih performansi od strane inspekcijskih timova. Može se zamisliti koliko bi ovo trajalo kada bi pojedinac vršio kontrolu ručnom termalnom kamerom.

Kontinuirana sigurnost i zaštita lokacije je takođe izuzetno kritična. Nakon što je instalirano na hiljade ploča, poslednje što se želi jeste da in neko ukrade ili da životinje sa susednog polja prekinu kablove. Dakle, korišćenje BL omogućava pristup čitavoj lokaciji iz vazduha, jer termalne kamere koje su tokom dana označavale hladne tačke na panelima sada imaju mogućnost da pronađu neovlašćena lica (životinje) koja se noću kreću po lokaciji solarne elektrane.

Vetrogeneratori su neizostavan energetski potencijal (Žikić i dr., 2020). Ispitivanje mesta za postavljanje vetroturbina i puštanje u rad skopčani su sa velikim logističkim i tehničkim problemima. Međutim, kada se vetrogeneratori puste u rad, potrebno je redovno praćenje njihovog stanja (Nachimuthu et al., 2019). Pregled vetrogeneratora pomoću BL fokusiran je na potencijalne strukturne probleme sa lopaticama, kao što su pukotine, udari groma, curenje ulja, erozija prednjih ivica (dok lopatice nailaze na čestice u vazduhu, cepaju se usled naprezanja lopatica i delaminacije ili odvajanje slojeva kompozitnih materijala koji čine oštrice). Od svih ovih problema, erozija, pukotine i odlaganje su najčešći, na različitim tačkama procesa degradacije. Visokokvalitetne kamere na BL mogu dati podatke operateru u kontrolnoj sobi na osnovu kojih će se odlučiti o daljem redosledu aktivnosti (slika 6).

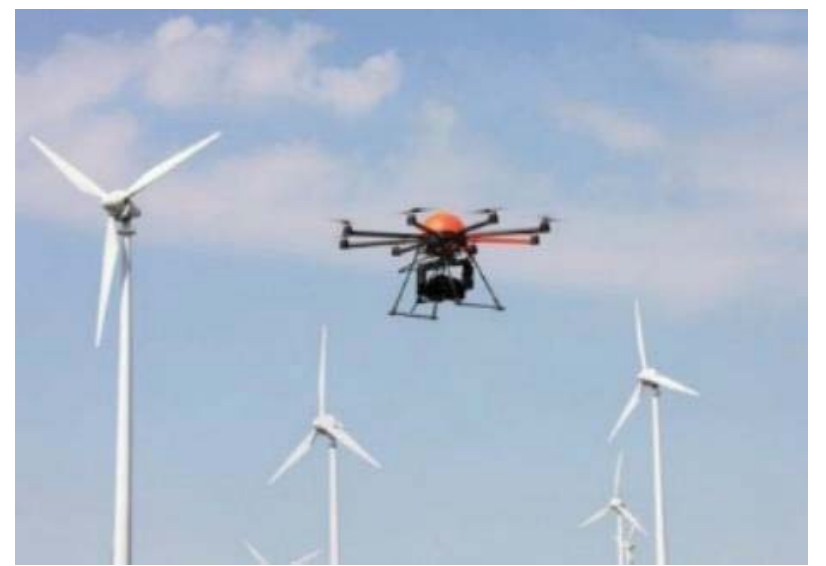

Slika 6 - Bespilotne letelice u kontroli vetrogeneratora

Figure 6 - Unmanned aerial vehicles in wind turbine control

\subsection{Primena bespilotnih letelica u inspekciji / Application of unmanned aerial vehicles in inspection}

Sve veći broj kompanija danas koristi tehnologiju bespilotnih letelica za vizuelni pregled, jer je to ekonomičan i efikasan način pregleda na visinama i nepristupačnim područjima. Način pregleda nedostupnih područja u zatvorenom i na otvorenom - i na moru i na kopnu.

Obično se pregled bespilotnim letelicama obavlja za (Nachimuthu et al., 2019):

1. Konstrukcije na moru - prikupljanje podataka odvija se u turbulentnom okruženju, dok su operater BL, inspektor i zaposleni izvan rizične zone na bezbednoj udaljenosti od područja inspekcije.

2. Kopnene konstrukcije - obično su BL ograničene na letenje na nadmorskoj visini do 100 metara. Međutim, može se navesti primer pregleda dimnjaka visine veće od 225 metara u rafinerijama, hidroelektranama ili nuklearnim elektranama. Još jedno područje koje je pogodno za inspekciju BL su mostovi, bez obzira na to što se nalaze na kopnu ili povezuju ostrva. Osim toga, BL daju dobre rezultate u pregledu vetrogeneratora.

3. Zatvoreni prostori - kao što su kotlovi u elektranama, skladišni rezervoari za gorivo itd., relativno su nova područja pregleda pomoću BL, ali postepeno postaju uobičajena.

Primena BL pruža sledeće prednosti: 1) brzi pregled i procena stanja, 2) jasne i detaljne fotografije nedostataka, 3) planiranje preventivnog održavanja i optimizacija proizvodnje, 4) pristup teško dostupnim područjima, 5) smanjeno vreme zastoja, 6) visok nivo bezbednosti (Duque et al., 2018).

Nuklearne elektrane su energetski objekti sa najstrožim bezbednosnim propisima. Propuštanje neke aktivnosti ili nesreća mogu imati nesagledive posledice po živote ljudi i životnu sredinu. Postupci inspekcije primenjuju se kako bi se izbegli dugoročni problemi čije je rešavanje izuzetno skupo. Sposobnosti $\mathrm{BL}$ da pregledaju ograničene prostore $\mathrm{i}$ područja izvan ljudskog vidokruga omogućavaju da se izvrše besprekorne procene i dobiju ključni podaci u nuklearnim elektranama bez ugrožavanja zaposlenih. Budući da su BL imune na zračenje, inspektori in mogu primeniti za prikupljanje podataka, čak i u najnepristupačnijim prostorima. Danas se BL koriste u preko $30 \%$ svih nuklearnih elektrana u SAD i time sprečava slanje radnika na fizičke preglede u radioaktivnom okruženju, čime se povećava bezbednost na radnom mestu (slika 7).

Opremljene Gajger-Milerovim detektorom, BL mogu detektovati zračenje tokom leta. Bespilotna letelica je opremljena sa tri senzora koji mogu meriti jačinu doze u rasponu od $3 \mu \mathrm{Sv} / \mathrm{h}$ do $10 \mathrm{~Sv} / \mathrm{h}$. Nakon inspekcijskog leta, nuklearni inženjeri mogu koristiti 
softver za mapiranje zračenja duž putanje leta BL, pokazujući tačnu lokaciju opasnih nivoa doze unutar nuklearnog objekta (Zhai i dr., 2014). Takođe, mogu da reprodukuju inspekcijski let koristeći ga za pregled merenja doze prikazanih sinhrono na video zapisu. Bespilotna letelica može se brzo rasporediti iz nezagađenog područja radi procene rizika i opasnosti u slučaju curenja ili akcidenta. Prilikom planiranja intervencija, BL se može koristiti za procenu ukupne doze kojoj bi radnici bili izloženi i identifikovanje žarišta kako bi se izloženost ljudi svela na minimum.

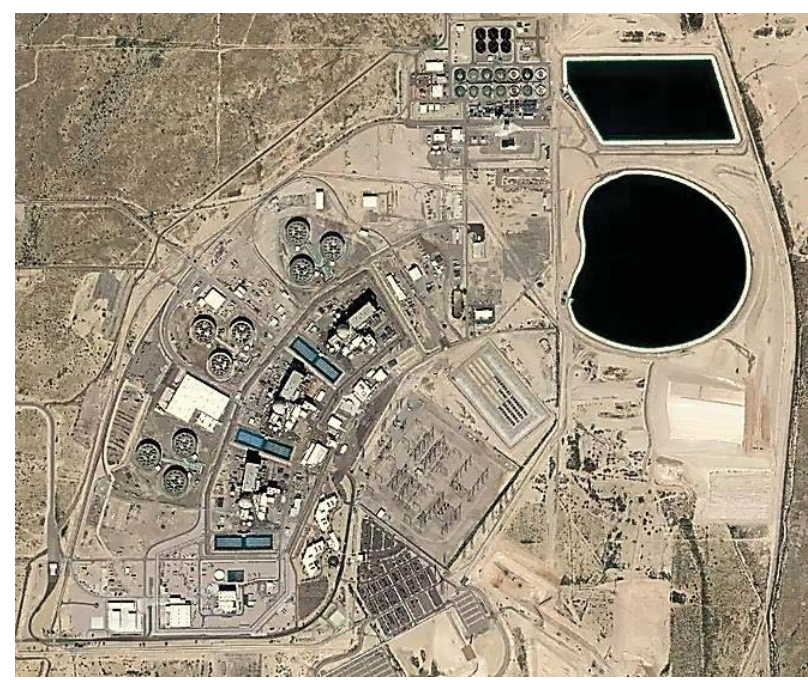

Slika 7 - Slika postrojenja nuklearne elektarne snimljena bespilotnom letelicom

Figure 7 - Photo of a nuclear power plant taken by an unmanned aerial vehicle

\subsection{Primena bespilotnih letelica u sagledavanju efekata klimatskih promena / \\ Application of unmanned aerial vehicles in considering the effects of climate change}

Kada govorimo o životnoj sredini, postoje dve reči koje se izdvajaju od ostalih: klimatske promene. Istraživanje klime je verovatno jedno od pionirskih polja u korišćenju BL u civilne svrhe. Već krajem 1990-tih, neki američki univerziteti su koristili BL za merenje promena arktičkog leda na mestima do kojih čovek nije mogao doći. lako se čini da nije prošlo mnogo vremena, BL i njihove mogućnosti su od tada značajno poboljšane. Po dimenzijama znatno manje, jeftinije i sa većom autonomijom leta, BL su bitna karakteristika u istraživanju klimatskih promena. Bespilotne letelice omogućavaju da brojimo životinjsku populaciju, detektujemo promene temperature morske vode ili merimo debljinu glečera. Brojni centri za istraživanje klime koriste BL u merenju atmosferskih događaja poput tropskih oluja i zimskih oluja i na taj način predviđaju njihovo ponašanje u budućnosti (Farinha i dr., 2020).

Na ekološkom planu, BL imaju hiljade aplikacija koje naučna zajednica tek počinje da otkriva, ali sve one imaju isti osnovni cilj - zaštititi planetu i budućnost čovečanstva. Najparadigmatičniji slučaj su Filipini, jedna od zemalja koja je najviše pogođena porastom temperature u okeanima, sa prosečno 20 rušilačkih tajfuna godišnje. Organizacija Ujedinjenih nacija za hranu i poljoprivredu (FAO) koristi BL u arhipelagu za smanjenje rizika od prirodnih katastrofa. Bespilotne letelice lete iznad ostrva proučavajući pejzaž i identifikujući najpogodnija područja za sađenje zaštitne vegetacije, izgradnju nasipa ili pronalaženje najboljih lokacija za izgradnju skloništa za stanovništvo. Kada je tajfun Haiyan pogodio jugoistočnu obalu Filipina 2013. godine, BL su korišćene za izradu detaljnih 2D baznih karata i 3D modela terena lokalnih četvrti, te procenu šteta i planiranje obnove skloništa (Kerr, 2015).

Okeanski ekosistemi su žila kucavica planete, a zdrav okean je neophodan za opšte zdravlje međusobno povezanih ekosistema širom sveta. Nažalost, mnogi ekosistemi okeana doživljavaju brzo propadanje, čije praćenje može pružiti uvid u sprečavanje dalje degradacije. Takođe, mnoge od ovih ekosistema je teško nadgledati, pa zaštitari ponekad koriste avione za prikupljanje podataka, što ima svoje granice i naravno znatan otisak $\mathrm{CO}_{2}$. Postoje i drugi, isplativiji pristupi, ali oni su često invazivni i mogu poremetiti ili uznemiriti divlje životinje. Ekolozi za okeane i zaštitnici prirode koriste BL kako bi dobili pogled na zdravlje okeana iz ptičje perspektive i neinvazivno praćenje megafaune u vodenim staništima - ajkula, raža i morskih kornjača.

Neki od najugroženijih okeanskih ekosistema su dubokomorski okeanski ekosistemi koji su uništeni prekomernim ribolovom. Stvaranje i zaštita utočišta u kojima je ribolov zabranjen ili ograničen može značajno doprineti obnavljanju ribljeg fonda u ovim ekosistemima. Obično će obalska straža ili drugi posmatrači nadzirati ovo utočište redovnim vazdušnim letovima. Nažalost, nailaze na iste probleme kao i zaštitnici prirode - letovi su skupi i ne pružaju isplativo pokriće. Kako bi eliminisali ograničenja $u$ korišćenju letova iz vazduha, zaštitari su počeli da koriste $\mathrm{BL}$ za monitoring zaštićenih područja. $\mathrm{Na}$ moru se BL koriste za monitoring područja kada brodovi i avioni nisu praktična opcija. lako još nisu u širokoj upotrebi, nekoliko manjih projekata je testiralo bespilotne letelice u praćenju okeana. Na primer, National Geographic finansira projekat SoarOcean (Howard, 2014) u kome se BL koriste za monitoring okeana. 


\subsection{Primena bespilotnih letelica u zaštiti divljih} životinja / Application of unmanned aerial vehicles in the protection of wild animals

Bespilotne letelice su odlično oruđe za praćenje populacije životinja i njihovog kretanja, a mogu lovokradice pre nego što ih napadnu tako što će ih locirati. Bespilotne letelice prate morske ptice u Australiji, spasili su šimpanze u Tanzaniji, orangutane na Sumatri, prebrojali foke u Kanadi i zelene kornjače u Indoneziji. Svetska fondacija za prirodu (WWF) i brazilska policija, na primer, koriste BL za praćenje lovokradica i ilegalne seče drveća (Hayes et al., 2021; Katanich, 2020).

Svetska fondacija za prirodu opisala je australijske požare 2019-2020. godine kao jednu od najgorih katastrofa divljih životinja u savremenoj istoriji. Nezapamćena sezona požara uništila je više od 12,6 miliona hektara zemlje širom kontinenta, ubivši ili raselivši gotovo 3 milijarde životinja. Od toga, više od 61.000 bile su koale. Nažalost, čak i pre krize sa požarima, koale su smatrane osetljivim na izumiranje zbog pretnji koje predstavljaju lov, degradacija zemljišta, nedostatak hrane, suše i bolesti. Dakle, kada su požari besneli, šumari i vatrogasci brzo su primenjivali $\mathrm{BL}$ kako bi tražili preživele koale $\mathrm{u}$ spaljenim i u nesagorelim područjima (Murison, 2020). U državi Viktorija, posada za hitne slučajeve koristila je $\mathrm{BL}$ sa termalnim kamerama visoke rezolucije kako bi otkrila toplotne otiske koala. Nakon što su koale locirane, vizuelna kamera sa ultrazumiranjem na istoj $\mathrm{BL}$ pomogla je da se utvrdi da li je životinjama potrebna medicinska pomoć. Naučnici u susednoj državi Novi Južni Vels takođe su se složili da su BL sa termalnim kamerama za mapiranje divljih životinja mnogo jeftinije i efikasnije od tradicionalnih metoda snimanja.

Bespilotne letelice su efikasna $i$ isplativa metoda praćenja ugroženih divljih životinja. Oni mogu pokriti dovoljno veliku površinu, a veštačka inteligencija BL omogućava njihovo mapiranje i brzu realizaciju letne rute. Upotreba BL za ispitivanje lokacija $\mathrm{i}$ divljih životinja sa rizikom od lovokradica i ugrožavanja korak je u pravom smeru za njihovu zaštitu. Operater BL mora imati prirodan pristup prilikom snimanja ciljanog područja jer je važno da ne plaše divlje životinje u njihovim prirodnim staništima. Niži nivo buke koji emituju BL manje će uplašiti životinje u poređenju sa pristupom rendžera protiv lovokradica. Bespilotne letelice mogu brojati životinje u okruženju preko podataka koje generišu i mogu programirati upozorenja za sve prepoznate potencijalne pritnje divljim životinjama i njihovim staništima. Ovi podaci su obično tačniji u poređenju sa tradicionalnim metodama (npr. rendžer koji fizički prebrojava životinje u jednom području).

\subsection{Diskusija / Discussion}

Nova tehnološka dostignuća doprinela su da se karakteristike pojedinih komponenti, uređaja i sistema drastično povećaju u kratkom periodu. Jedni od takvih su senzori svih mogućih mernih područja, kao i minijaturizovane kamere. Kada se ugrade na odgovarajuće platforme (u ovom slučaju bespilotne letelice), omogućavaju pretraživanje zemljišta, vodotokova, morskih površina, snimanje i inspekciju visokoodgovornih energetskih objekata (elektrane, vetrogeneratori, cevovodi i gasovodi, naftne platforme), praćenje divljih životinja na njihovim staništima itd., generisanjem snimaka visoke rezolucije u realnom vremenu. Dijapazon komercijalnih primena BL je izuzetno veliki i svakodnevno se menjaju ambijenti i uslovi u kojima je njihova primena adekvatna zahtevima klijenata. Iz navedenih primera očigledno je da BL imaju perspektivu i da se tržište ovih proizvoda eksponencijalno povećava.

\section{ZAKLJUČAK / CONCLUSION}

$\mathrm{U}$ poslednjih nekoliko godina, razgovor o tehnologiji bespilotnih letelica i njihovoj upotrebi nastavlja da se zahuktava. Šira javnost želi da zna kakva je budućnost BL i kakav će uticaj imati na naš svakodnevni život. Međutim, ne sme se zanemariti neverovatan napredak koji je već ostvaren u rešavanju današnjih poslovnih problema u stvarnom svetu, koji otvara put za budući razvoj u autonomiji, logistici i brzoj digitalizaciji fizičkog sveta. Mnogo toga se može pripisati sposobnostima senzora $\mathrm{i}$ analizi podataka u odnosu na same BL, što postavlja temeljne blokove za budućnost u kojoj će svaki aspekt našeg života na neki način biti pogođen tehnologijom bespilotnih letelica. Zamah postoji, komercijalne aplikacije se povećavaju, a mogućnosti za tehnologiju su beskrajne.

\section{LITERATURA / REFERENCES}

[1] Chen, H. F., Ming, W. T., Chi, L-P., Zhuang, Z-Y. (2021). On the Dominant Factors of Civilian-Use Drones, Drones, 5(46), pp. 46-77.

[2] Congressional Research Service (2019). International Illegal Logging: Background and Issues, February 26, Washington.

[3] Direktorat civilnog vazduhoplovstva (2020). Pravilnik o bespilotnim vazduhoplovima, SI. glasnik RS, br. 1/2020.

[4] Drone Industry Insights. The Drone Market Report 2020-2025. Dostupno na:

https://droneii.com/product/drone-market-report2020-2025.

[5] Duque, L., Seo, J., Wacker, J. (2018). Synthesis of unmanned aerial vehicle applications for infrastructures, J. Perform. Constr. Facil., 32(4), pp. 1-10. 
[6] FAO (2021). The impact of disasters and crises on agriculture and food security, Roma.

[7] Farinha, A., Zufferey, R., Zheng, P., Armanini, S., Kovac, M. (2020). Unmanned Aerial Sensor Placement for Cluttered Environments, IEEE Robotics and Automation Letters, 5(4), pp. 6623-6630.

[8] Federal Aviation Administration (2016). Remote Pilot - Small UAS, Washington, DC.

[9] Hassanalian, M., Abdelkefi, A. (2017). Classifications, applications, and design challenges of drones: A review, Prog. Aerosp. Sci., 91, pp. 99131.

[10] Hayes, M., Gray, P., Harris, G., Sedgwick, W., Crawford, V., Chazal, N., Crofts, S., Johnston, D. (2021). Drones and deep learning produce accurate and efficient monitoring of large-scale seabird colonies, Americal Ornitology, 123, pp. 1-16.

[11] Howard, B. C. (2014). Can Drones Fight Illegal "Pirate" Fishing? Dostupno na:

https://www.nationalgeographic.com/adventure/a rticle/140718-drones-illegal-fishing-pirate-belizeocean

[12] Jang, G.J., Kim, J., Yu, J.K., Kim, H.J., Kim, Y., Kim, D.W., Kim, K.H., Lee, C.W., Chung, Y.S. (2020). Review: Cost-effective UAV platform for field plant breeding application, Remote Sens., 12(6), pp. 998-1017.

[13] Kardasz, P., Doskocz, J., Hejduk, M., Wiejkut, P., Zarzycki, H. (2016). Drones and Possibilities of Their Using, Journal of Civil \& Environmental Engineering, 3(3), pp. 233-239.

[14] Katanich, D. (2020). Drones expose real number of endangered species left on the planet. Dostupno na: https://www.euronews.com/green/2020/ 06/12/drones-expose-real-number-ofendangered-species-left-on-the-planet

[15] Kerr, D. (2015). Drones' newest mission? Disaster relief. Dostupno na: https://www.cnet.com/ news/drones-newest-mission-disaster-relief/

[16] Lee, D.H., Park, J. H. (2019). Developing Inspection Methodology of Solar Energy Plants by Thermal Infrared Sensor on Board Unmanned Aerial Vehicles, Energies, 12(15), pp. 2928-2941.

[17] Krishna, K.R. (2017). Agricultural drones: a peaceful pursuit, Apple Academic Press, Palm Bay.

[18] Mentus, S., Jovanović, L. (2020). Napredne tehnologije u sprečavanju klimatskih promena, Ecologica, 27(100), 579-588.

[19] Murison, M. (2020). How Drones are Saving Koalas Injured in Australia's Bushfires. Dostupno na: https://dronelife.com/2020/02/12/how-dronesare-saving-koalas-injured-in-australias-bushfires/

[20] Nachimuthu, S., Zuo, M.J., Ding, Y. (2019). A decision-making model for corrective mainten- ance of offshore wind turbines considering uncertainties, Energies, 12(8), pp. 1408-1420.

[21] Petkovics, I., Simon, J., Petkovics, A., Covic, Z. (2017). Selection of UAV for precision agriculture with multi-criteria decision-making algorithm, Proc. of the 15th Int. Symp. SISY, Subotica, pp. 151-156.

[22] Ristić, Z., Džafić, G., Jevremović, M., Damnjanović, A. (2020). Nove tehnologije - izazovi za kompanije i održiv ekonomski razvoj, Ecologica, 27(99), str. 401-406.

[23] Sah, B., Gupta, R., Bani-Hani, D. (2020). Analysis of barriers to implement drone logistics, Int. J. Logist. Res. Appl., pp 1-22.

[24] Samaniego, J. (2017). These drones have a special mission: saving the planet. Dostupno na: https://blog.ferrovial.com/en/2017/06/drones-forenvironmental-monitoring/

[25] Simelli, I., Tsagaris, A. (2015). The Use of Unmanned Aerial Systems (UAS) in Agriculture, Proceedings of 7th Int. Conf. HAICTA, pp. 730-736.

[26] Srivastava, K.; Pandey, P.C.; Sharma, J.K. (2020). An Approach for Route Optimization in Applications of Precision Agriculture Using UAVs, Drones, 4(3), pp. 58-80.

[27] Sylvester, G. (2018). E-Agriculture in action: drones for agriculture. Food and Agriculture Organization of the United Nations and International Telecommunication Union, Bangkok.

[28] World Bank (2019). Illegal logging, fishing, and wildlife trade: The costs and how to combat it, Washington, DC.

[29] Yu, S.H., Kim, Y.K., Jun, H.J., Choi, I.S., Woo, J.K., Kim, Y.H., Lee, J. (2020). Evaluation of Spray Characteristics of Pesticide Injection System in Agricultural Drones, J. Biosyst. Eng., 11(5), pp. 1-9.

[30] Zhai, S., Bai, B.(2014). A Time Service Improvement Scheme for Clock System of Nuclear Power Plant, Int. J. Comput. Electr. Eng., 6(6), pp. 501-506.

[31] Zhang, C., Kovacs, K. (2012). The application of small unmanned aerial systems for precision agriculture: a review, Precision agriculture, 13(6), pp. 693-712.

[32] Zhou, M., Zhou, Z., Liu, L., Huang, J., Lyu, Z. (2020). Review of vertical take-off and landing fixed-wing UAV and its application prospect in precision agriculture, Int. J. Precis. Agric. Aviat., 3, pp. 8-17.

[33] Žikić, S., Nestorović, M., Stevanović, M. (2021). Ekonomski, ekološki i društveni aspekti održivog upravljanja obnovljivom energijom, Ecologica, 28 (101), str. 57-64. 